\title{
A Study on Hysteroscopy as a Primary Diagnostic Modality in Patients of Abnormal Uterine Bleeding
}

\author{
Malvika Misra ${ }^{1 *}$, DR Chandravati ${ }^{2}$ \\ ${ }^{1}$ Assistant Professor, Department of Obstetrics and Gynecology, Dr. Ram Manohar Lohia Institute of Medical Sciences, \\ Lucknow, India \\ ${ }^{2}$ Emeritus Professor, Department of Obstetrics and Gynecology, Krishna Medical Centre, Lucknow, India
}

*Address for Correspondence: Dr. Malvika Misra, Assistant Professor, Department of Obstetrics and Gynecology, Dr. Ram Manohar Lohia Institute of Medical Sciences, Lucknow, India

E-mail: drmalvikam@gmail.com

Received: 12 Apr 2019/ Revised: 19 Jul 2019/ Accepted: 22 Aug 2019

\begin{abstract}
Background: Among women, abnormal uterine bleeding and infertility rates are rapidly increasing. The clinician generally prefers physical examination, methodical histopathology report to diagnose the pregnancy related disorders, systemic conditions and disease related to the genital tract. Diagnostic hysteroscopy is a precious contrivance to diagnose widespread disorders and diseases related to female genital tract and uterus, such as abnormal uterine bleeding since hysteroscopy assists to understand the mechanism for the regulation of normal cycle.

Methods: The study had been carried out in the Department of Obstetrics and Gynecology, Krishna Medical Center, Lucknow from September 2012 to July 2017. Total of 400 patients were included in this randomized study. The study allocated histopathologic analysis, diagnostic hysteroscopy, intervention with or without anesthesia and postoperative diagnosis of patients.

Results: Of all the cases, who underwent diagnostic hysteroscopy, about $44 \%$ of cases were normal and $56 \%$ of cases were found with various abnormalities. $22 \%$ of cases had endometrial hyperplasia, $11 \%$ of cases had an endometrial polyp, $10 \%$ of cases had submucous myoma and $9 \%$ of cases had atrophy. On observing the clinical presentation, $42 \%$ of cases had menorrhagia, $20 \%$ of cases had polymenorrhoea, $16 \%$ of cases had metorrhagia and $22 \%$ of cases had reported with postmenopausal bleeding. About $60 \%$ of diagnostic hysteroscopies were performed without anesthesia, however, an ascending trend was reported for general anesthesia. Primary infertility was reported in $44 \%$ of cases and $56 \%$ of cases were reported with secondary infertility.

Conclusion: Our study concluded that the patients with pregnancy-related disorders and disease related to the genital tract and uterus should first undergo diagnostic hysteroscopy to provide a diagnosis with high accuracy and specificity.
\end{abstract}

Key-words: Abnormal Uterine bleeding, Anesthesia, Diagnostic hysteroscopy, Infertility, Tamoxifen therapy

\section{INTRODUCTION}

Abnormal uterine bleeding (AUB) becomes a common gynecological problem encountered in the family practice setting, with complicated clinical presentations. A regular history, physical examination, and laboratory evaluation possibly enables a clinician to find out the causes of disorders related to fertility such as genital tract pathology, iatrogenic causes, as well as medications in women under childbearing age ${ }^{[1]}$.

\section{How to cite this article}

Misra M, Chandravati DR. A Study on Hysteroscopy as a Primary Diagnostic Modality in Patients of Abnormal Uterine Bleeding. SSR Inst. Int. J. Life. Sci., 2019; 5(5): 2393-2401.

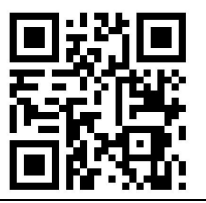

A national study on mechanism of abnormal uterine bleeding reported those over a period of 10 years, menstrual disorder were observed in $19 \%$ of 20 million patient visits to a physician's clinic for gynecologic condition ${ }^{[2]}$. Besides this, $25 \%$ surgeries at gynecologist clinic were done to treat abnormal uterine bleeding. Women experienced several changes in frequency of the menstrual period, duration of menstrual period, or quantity of flow, as well as bleeding among two cycles ${ }^{[2,3]}$. The abnormal uterine bleeding in postmenopausal women, vaginal bleeding after 12 months or more of cessation of menses, and/or irregular bleeding in postmenopausal women who have been getting 12 month or more then 12 month hormone therapy ${ }^{[4,5]}$. The first contemplation is pregnancy for women of childbearing age facing $A \cup B{ }^{[6]}$. The most possible 
reasons behind pregnancy-related bleeding comprise of spontaneous pregnancy loss, ectopic pregnancy, placenta previa, abruptio placentae, and trophoblastic disease ${ }^{[3,7]}$. Patients are supposed to have queries regarding patterns, contraception, and activity related to reproductive life. In establishing pregnancy-related disorders, a number of examinations are done, including bimanual pelvic examination, a beta-subunit human chorionic gonadotropin test as well as transvaginal sonography ${ }^{[8]}$. Subsequently, iatrogenic reasons of abnormal uterine bleeding should be investigated. Medication might be the reason behind the onset of bleeding, which includes anticoagulants, reuptake inhibitors of selective serotonin, antipsychotics, corticosteroids, hormonal medications, and tamoxifen. Ginseng, ginkgo, and soy supplements are few herbal substances that alter the estrogen levels and parameters of clotting, and therefore they may cause menstrual irregularities ${ }^{[5]}$. The evaluation of abnormal uterine bleeding significantly depends on the age of the patient, risk factors associated with endometrial cancer includes high body mass index (BMI), anovulatory cycles, nulliparity, age exceeding 35 years and tamoxifen therapy ${ }^{[8]}$. Medical management is recommended for patients at low risk for endometrial carcinoma in premenopausal women who are diagnosed with presumed dysfunctional uterine bleeding. Endometrial evaluation of subtle genital tract pathology is suggested for patients having high risk of endometrial cancer as well as at low risk, who keep abnormally bleeding continuously despite of medical management ${ }^{[9]}$.

Recently, hysteroscopy is the most accepted procedure for the analysis and/or for treatment of various pathologies of the endometrial cavity, tubal ostia and/or endocervical canal for diagnosis alone or for diagnostic and operating procedure in the same sitting ${ }^{[10,11]}$. A review article published in 2011, introduces the diagnostic and operative indications for hysteroscopy. It includes abnormal uterine bleeding, which might be premenopausal or postmenopausal, sub-mucosal, endometrial polyps, intramural, intrauterine adhesions, fibroids, and Mullerian anomalies retained products of conception and intrauterine devices or other foreign bodies and endocervical polyps ${ }^{[5,10]}$. Several conditions such as viable intrauterine pregnancy, active pelvic infection, uterine cancer or cervical cancer are contraindications to hysteroscopy ${ }^{[11]}$. The probabilities to carry out hysteroscopy without anesthesia or with local anesthesia allocate outpatient settings and speedy recovery. The vaginoscopic technique is carried out, that is devoid of tenaculum or speculum, and anesthesia ${ }^{[12]}$. Mostly the diagnosis and the minor operations can be done without anesthetic or can be performed with a local anesthetic ${ }^{[13]}$. General or regional anesthesia is ideal for patients undergoing extensive operative procedures, or patients with comorbidities that necessitate intensive monitoring ${ }^{[14,15]}$. Dilation and Curettage (D\&C) are traditionally used to evaluate abnormal uterine bleeding. It is a blind procedure and the endometrium is transported to pathologist for the analyses of histological patterns and reporting ${ }^{[1,16]}$. The procedure completely depends on co-operation of the pathologist to get outcomes; therefore the procedure is believed to be less accurate.

The study has been undertaken to evaluate the indication for diagnostic hysteroscopy, type of anesthesia used during the procedure, the role of hysteroscopy for evaluation of abnormal uterine bleeding and finding accuracy among hysteroscopy and histopathology via comparative analysis. The study also focused towards the adverse condition affecting the fertility of patients. Furthermore, the study also evaluated the ratio and percentage of cases facing abnormal uterine bleeding, subsequent to the completion of procedure or treatment.

\section{MATERIALS AND METHODS}

The present "randomized study" was an approach to overcome the failure of abnormal uterine bleeding treatment. The study had been carried out in the Department of Obstetrics and Gynecology, Krishna Medical Center, Lucknow, India from September 2012 to July 2017. The subject included 400 patients that had been attended OPD and underwent hysteroscopy and $D \& C$ subsequent to the exclusion of comorbid illness.

\section{Inclusion criteria}

1. Patients had age between 20 to 60 years with AUB

2. Multiparous, nulliparous and grand multiparous

3. Patients did not require emergency treatment ${ }^{[16]}$

\section{Exclusion criteria}

1. Patients with profuse bleeding and large fibroids or multiple fibroids.

2. Cases having genital tract infection and genital tract malignancies ${ }^{[16]}$ 
Before proceeding to hysteroscopy, the investigations were done, including PAP smear, vaginal bacteriologic tests, haemograms ${ }^{[17]}$. The patients were subjected to detailed history taking, physical examination as well as specific examination in the form of per speculum and per vaginal examination. Blood investigations and urine investigations include hemoglobin $(\mathrm{Hb} \%), A B O$ and Rhesus (Rh), blood sugar level, time of bleeding, time is taken while blood clotting, aPTT, INR urine routine and microscopy were ordered for all patients ${ }^{[18]}$. TVS of all the patients were done. Detailed information of all the patients was obtained before taking up for any procedure ${ }^{[15]}$. Hysteroscopy and diagnostic D\&C were done for each of these patients. Hysteroscopic-guided curetting were taken and sent for histopathological analysis. The findings at USG, D\&C reports, hysteroscopy were compared with each other. The procedures were done under anesthesia in the operation theater. Generally, the antibiotics were not routinely administered during hysteroscopy for avoiding surgical site infection or endocarditis as post hysteroscopy infection occurred in less than $1 \%$ of women ${ }^{[12]}$. Antibiotics were not regularly prescribed during the procedure $^{[15]}$.

\section{RESULTS}

Hysteroscopy was carried out in this study by means of 5 $\mathrm{mm}$ hysteroscope with 30 degrees oblique lens in patients of abnormal uterine bleeding and was performed from September 2012 to July 2017. The study was conducted with a group of 400 patients who were presented with abnormal uterine bleeding. The endometrium was transported to pathology for histopathological investigations.

In the present study, maximum numbers of patients were between 40-49 years of age. The oldest patient was 52 years old and youngest one was about 22 years old. $17.5 \%$ patient's age incidences between 20-29 years, $16 \%$ patient's age incidences between 30-39 years, $0.75 \%$ patient's age incidences between 50-60 years, however the maximum number of patients incidence between $40-49$ years that were $65.75 \%$ of all the patients.

The 16 patients of age between 20-29 years had less than 6 months of symptoms, however, 72 patients of age between 40-49 years had symptoms for 6 months to 1 year and 64 patients of the same age group had symptoms for 1 year. Only 2 patients of the age group between 50-60 years had 6 months to 1 year of symptoms and only single case was reported symptoms for 1 year (Fig. 1). About 53\% of patients were multiparous and belong to the age group between 40-49 years. Nulliparity was observed in $15 \%$ in patients between 20-29 years of age (Fig. 2).

Polymenorrhoea was a frequent clinical presentation in patient of age between 40-49 years and menorrhagia were mostly observed in patients of age between 30-39 years. The clinical presentations for patients of the age group between 20-29 years were not specified shown in Table 1.

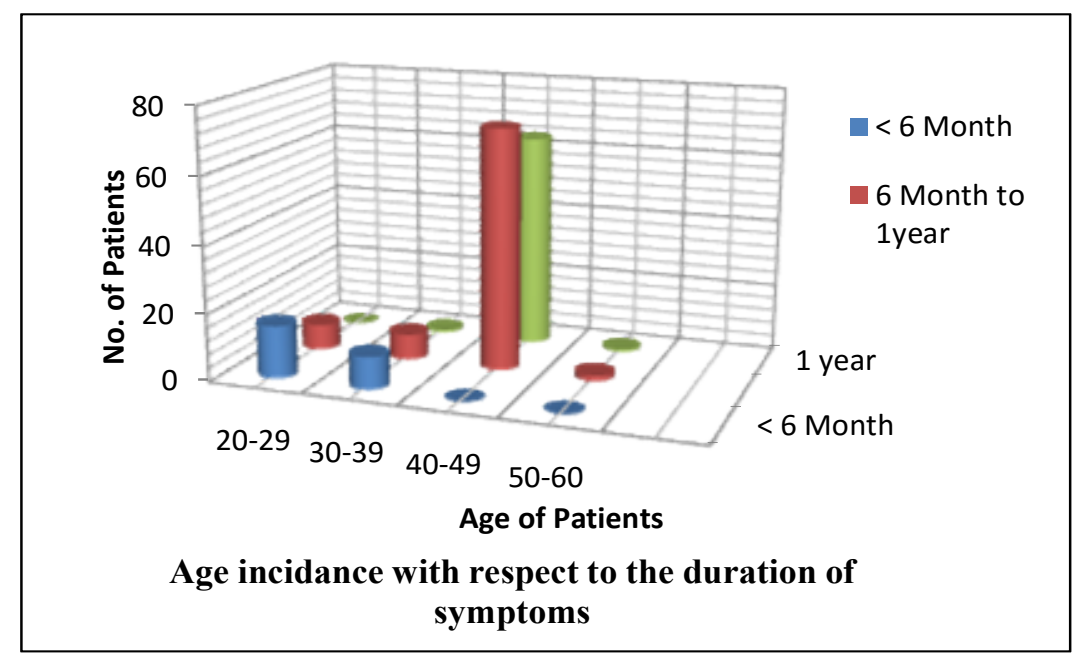

Fig. 1: Distribution of Patients according to age, having Symptoms of Abnormal menstrual cycle and uterine bleeding 


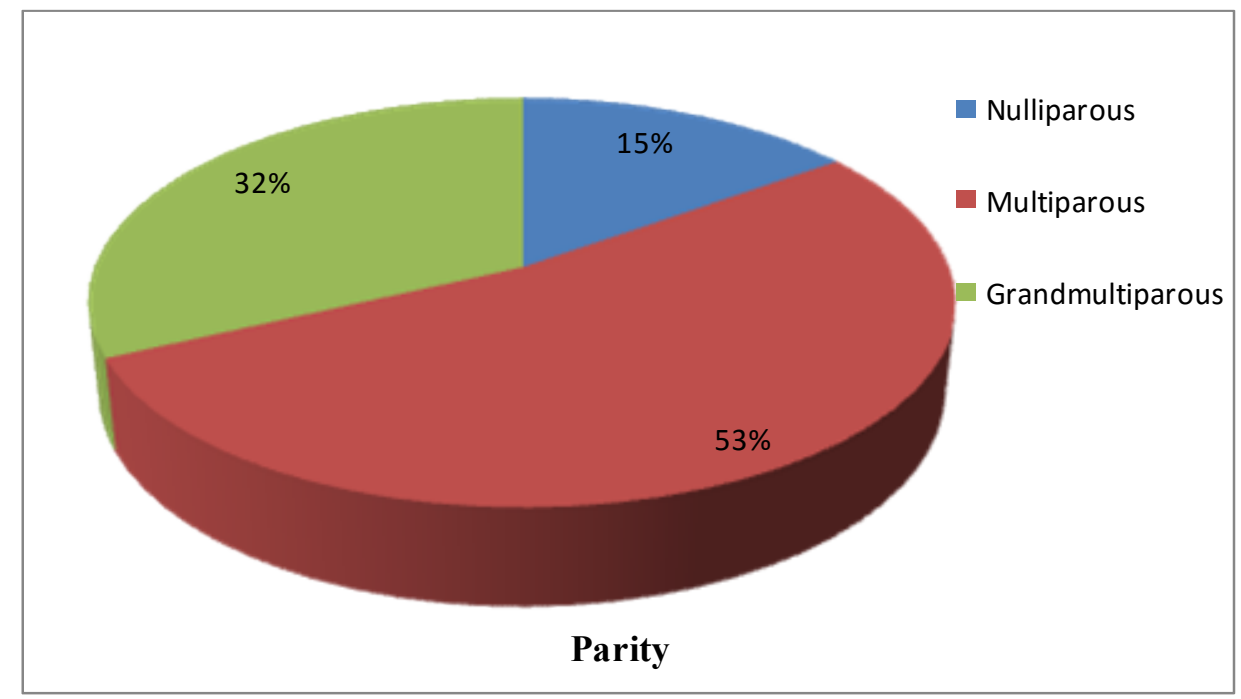

Fig. 2: Distribution of types of parity observed in patients of AUB

Table 1: Clinical presentation: Observation according to Age and evaluated conditions

\begin{tabular}{ccccccc}
\hline Clinical presentation & $\begin{array}{c}\text { Total no. } \\
\text { of Patients }\end{array}$ & $\begin{array}{c}\mathbf{2 0 - 2 9} \\
\text { (Years) }\end{array}$ & $\begin{array}{c}\mathbf{3 0 - 3 9} \\
\text { (Years) }\end{array}$ & $\begin{array}{c}\mathbf{4 0 - 4 9} \\
\text { (Years) }\end{array}$ & $\begin{array}{r}\mathbf{5 0 - 6 0} \\
\text { (Years) }\end{array}$ & $\begin{array}{c}\text { Percentage } \\
\text { (\%) }\end{array}$ \\
\hline Menorrhagia & 168 & 9 & 72 & 87 & 0 & 42 \\
Polymenorrhoea & 80 & 15 & 38 & 27 & 0 & 20 \\
Metorrhagia & 64 & 0 & 37 & 27 & 0 & 16 \\
$\begin{array}{c}\text { Postmenopausal } \\
\text { Bleeding }\end{array}$ & 88 & 0 & 0 & 27 & 61 & 22 \\
\hline
\end{tabular}

The types of anesthesia used for the hysteroscopy showed predominance of involvement carried out without any anesthesia. Usually, general anesthesia with orotracheal intubation was recommended for combined interventions or major hysteroscopic surgeries i.e. myomectomy or metroplasty with a descending trend between 2012 and 2017 from 10\% to 7\%. We have observed a slight ascending trend for utilization of general anesthesia with sedation between 2012 and 2017 from 20\% to 22\% (Fig. 3). Diagnostic hysteroscopy was performed without anesthesia in $60 \%$ to $62 \%$ cases. The use of anesthesia in this study is graphically represented in Fig. 3.

Hysteroscopy findings suggested that most of the patients were experiencing endometrial hyperplasia. Total $22 \%$ of patients were found to have endometrial hyperplasia, $10 \%$ with submucous myoma followed by $11 \%$ endometrial polyp and $9 \%$ endometrial atrophy (Fig.
4A). The outcomes of histopathology revealed that $56 \%$ of patients had no abnormalities and $23 \%$ of patients had endometrial hyperplasia followed by $11 \%$ of cases with endometrial atrophy. The histopathology finding suggested that $56 \%$ patients were normal, $23 \%$ patients were found to have endometrial hyperplasia, $0 \%$ with submucous myoma followed by $6 \%$ endometrial polyp and $11 \%$ with endometrial atrophy. Minority $4 \%$ of the cases reported with irregular shedding (Fig. 4B). While diagnosing the abnormalities, the hysteroscopy and histopathology were accurate with a specificity of $94.9 \%$ and PPV (positive predictive value) of about $97.01 \%$ and $94.66 \%$. The lesion was diagnosed comparatively more frequently with hysteroscopy due to $91 \%$ of sensitivity in comparison to curettage having only $68.89 \%$ of sensitivity. The final diagnosis and accuracy of hysteroscopy and histopathology are summarized in Fig. 5. 


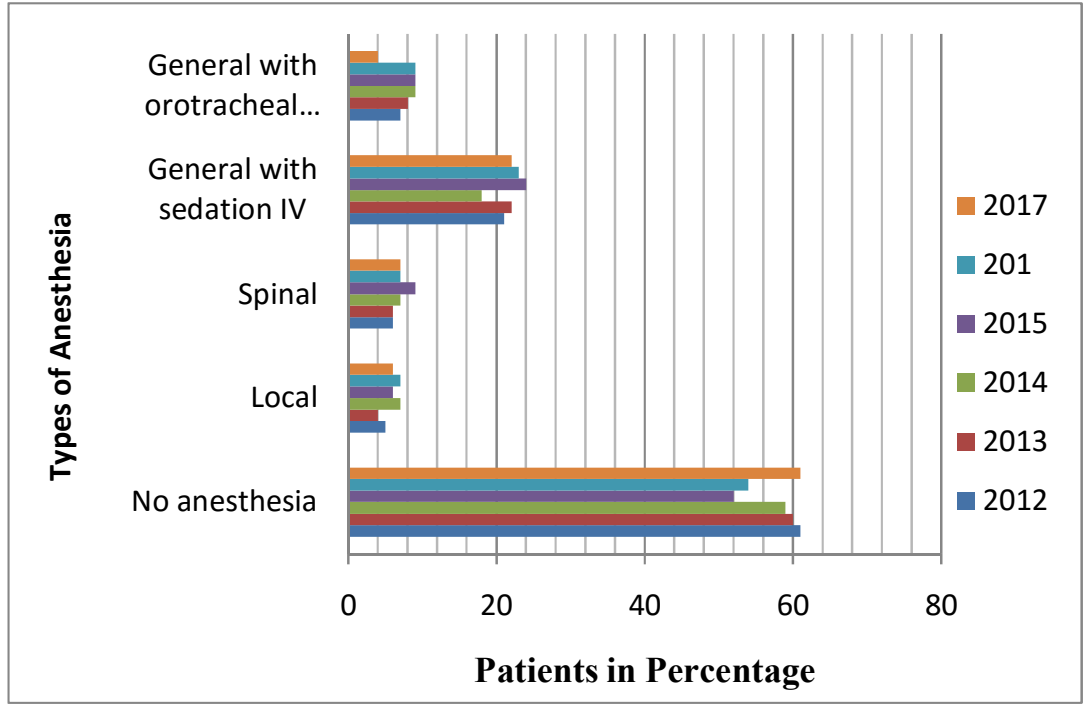

Fig. 3: Anesthesia given to the patient for hysteroscopy
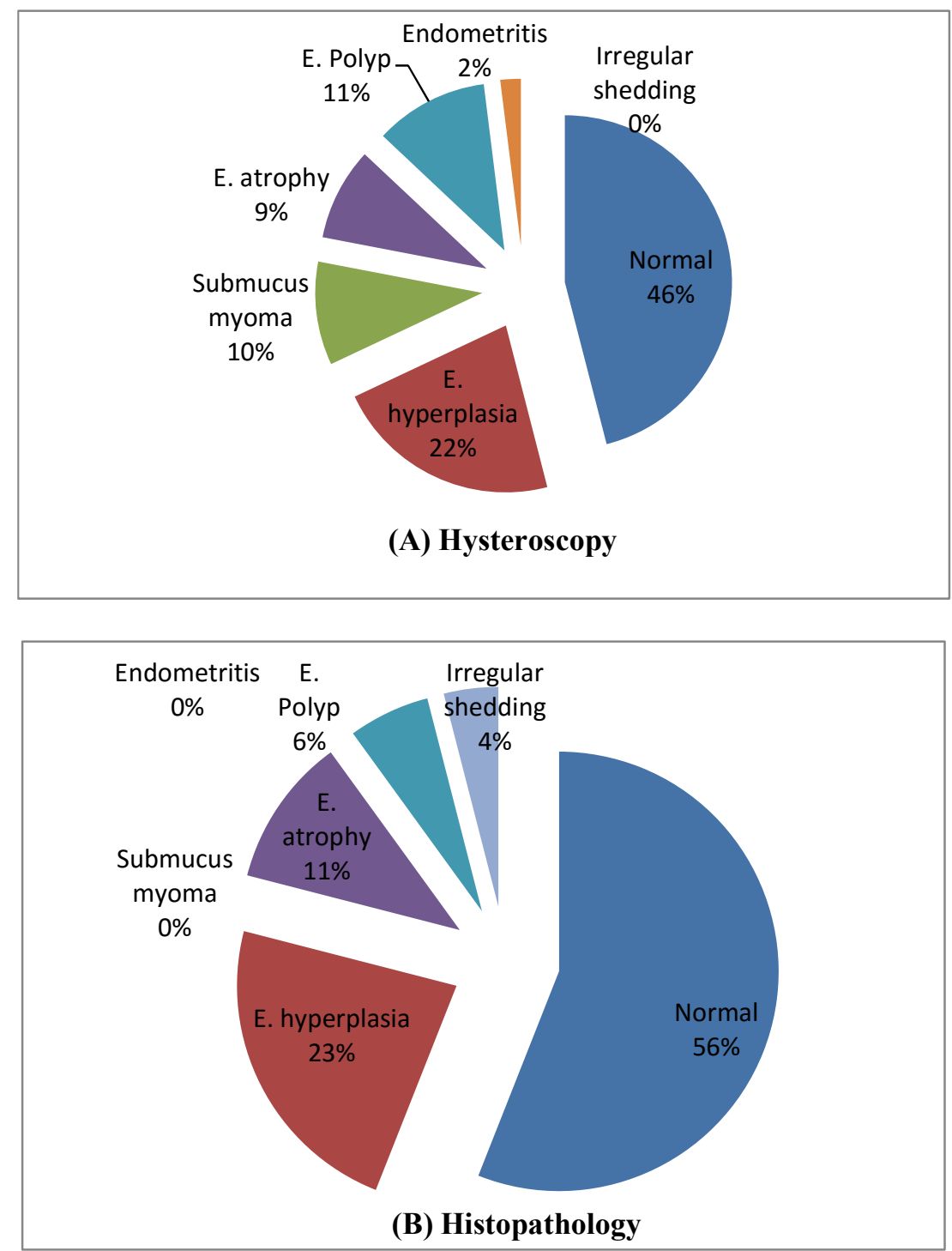

Fig. 4: (A) Hysteroscopy findings and (B) Histopathology findings from patients $\mathrm{E}=$ Endometrial 


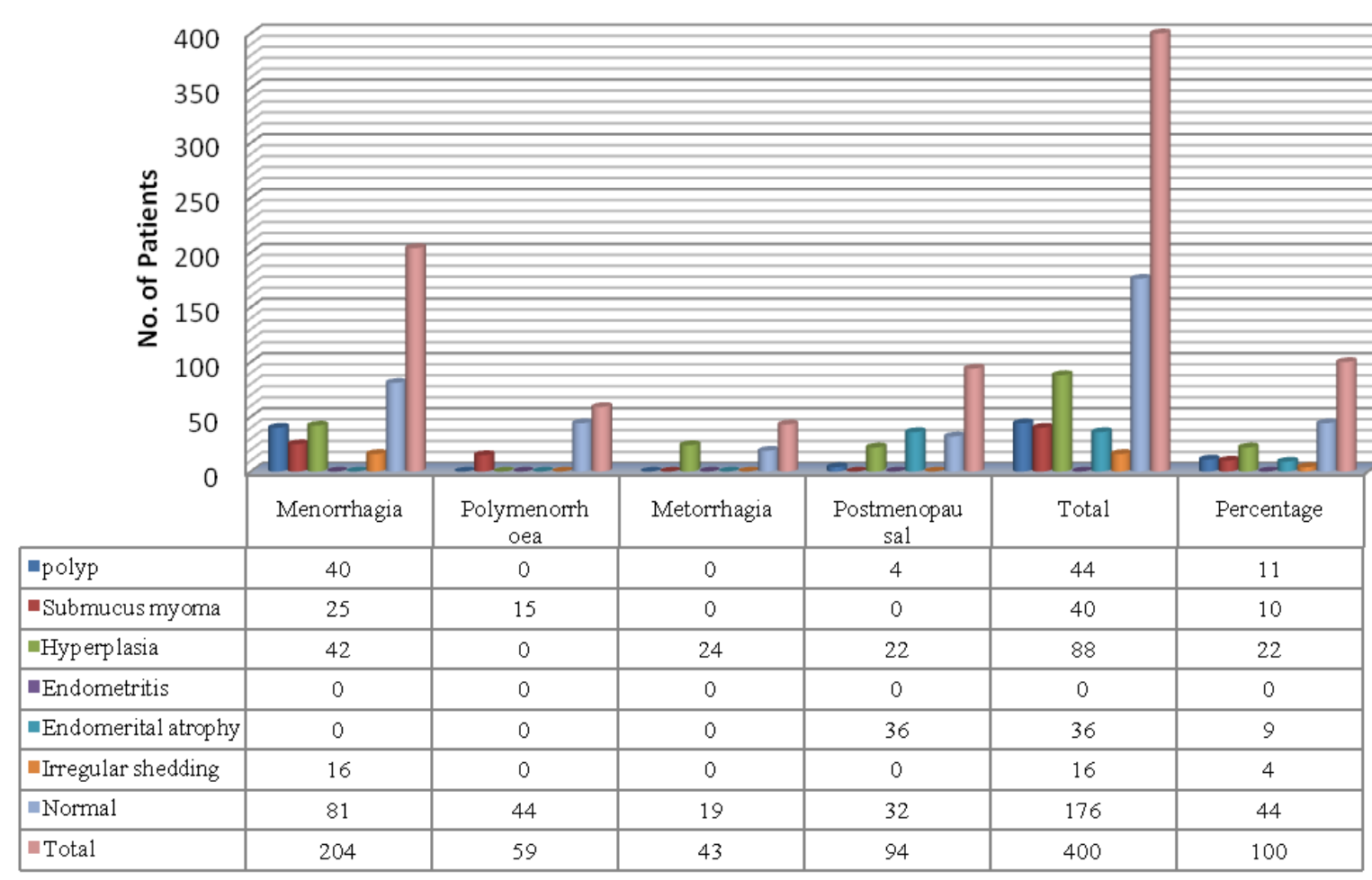

Accurate observations after Hysteroscopy and Histopathology

Fig. 5: Final outcomes obtained through diagnostic hysteroscopy and histopathology

From the abnormal cases (patient), $44 \%$ of cases were reported with primary infertility and $56 \%$ of cases with secondary infertility (Table 2). The pathology diagnoses for abnormal uterine bleeding in patients were shown by the graph (Fig. 6). Endouterine pathology was not observed in $26 \%$ cases. In $19 \%$ of cases, hysteroscopy concluded endometrial cavity, requiring curettage biopsy for endometrial hyperplasia. In $21 \%$ of cases, focal pathology was detected (focal hyperplasia of the endometrium and small polyps), which was followed by hysteroscopic biopsy, about $16 \%$ were represented by the intra-cavitary foreign bodies and impacted IUD, 3\% of endometrial polyps and $3 \%$ of sub-mucosal myoma.

Table 2: Hysteroscopy: Primary infertility and secondary infertility Cases

\begin{tabular}{cccccccc}
\hline $\begin{array}{c}\text { Infertility } \\
\text { stages }\end{array}$ & $\begin{array}{c}\text { Norma } \\
\text { I (\%) }\end{array}$ & $\begin{array}{c}\text { Tubal } \\
\text { unilateral } \\
\text { (\%) }\end{array}$ & $\begin{array}{c}\text { Tubal } \\
\text { bilateral (\%) }\end{array}$ & Polyps (\%) & $\begin{array}{c}\text { Endometritis } \\
\text { (\%) }\end{array}$ & $\begin{array}{c}\text { Uterine } \\
\text { septum (\%) }\end{array}$ & $\begin{array}{c}\text { Myoma } \\
\text { (\%) }\end{array}$ \\
\hline $\begin{array}{c}\text { Primary } \\
\text { infertility }\end{array}$ & 45 & 09 & 19 & 11 & 02 & 04 & 10 \\
$\begin{array}{c}\text { Secondary } \\
\text { infertility }\end{array}$ & 41 & 25 & 29 & 02 & 01 & 01 & 01 \\
\hline
\end{tabular}




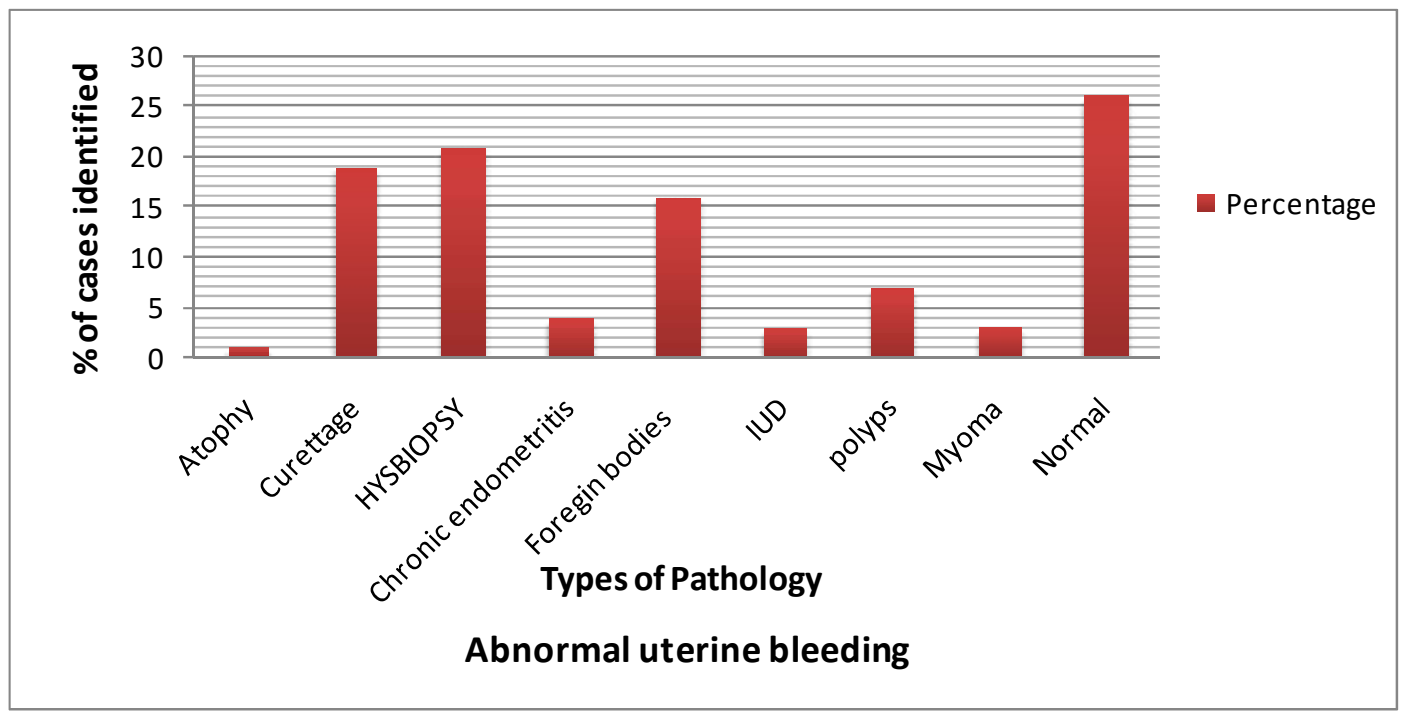

Fig. 6: Data of different Pathology for abnormal uterine bleeding

Whereas- Hys biopsy- Hysteroscopic biopsy; IUD- Intrauterine devices

\section{DISCUSSION}

This study was done with the patients of the age group between 20-60 years. However the maximum abnormalities were observed in cases of age between $35-45$ years. The study given by Panda et al. ${ }^{[19]}$ identified that the maximum age incidence between $35-45 \mathrm{yrs}$ and the range of age in Gianninoto's series was $38-40$ years and consequently most common incidence was between 30-45 yrs, however, Trotsenburg acknowledged the maximum age incidence between $41-50$ yrs ${ }^{[18,19]}$.

The most common clinical symptoms presented in this study was menorrhagia in $42 \%$ of cases. Postmenopausal bleeding was present in $22 \%$ cases and $20 \%$ cases shown Polymenorrhoea ${ }^{[20]}$. The series given by Panda et al. ${ }^{[19]}$ recognized menorrhagia in $60 \%$ of cases followed by Polymenorrhagia and Metrorrhagia [15,21]. In our study, $46 \%$ were found normal on hysteroscopy whereas $54 \%$ of patients were identified with abnormal symptoms related to reproductive health. Since 1999, the specialists of reproductive gynecology have disputes regarding the inclusion of hysteroscopy in infertility investigation. Hysteroscopy detected endometrial polyp, submucous fibroid and all cases of endometrial hyperplasia accurately ${ }^{[15,20]}$. European society of human reproduction and embryology conducted a study on hysteroscopy with endometrial biopsy and thus concluded that the hysteroscopy with endometrial biopsy is the "Gold standard" to investigate abnormal uterine bleeding ${ }^{[19-22]}$. Dilatation and curettage was considered as obsolete because it is a blind procedure with a complication rate of $6 \%$ to $8 \%$ and low sensitivity for local and pedunculated intracavitary lesions ${ }^{[9,16]}$. The Lesions were more accurately visualized through hysteroscopy therefore biopsy can be done simultaneously. A study carried out at the University of Wisconsin, Madison evaluated that the hysteroscopy with biopsy allocates the visualization of the endometrial cavity and is considered as the gold standard for endometrial assessment ${ }^{[23]}$.

The series provided by specialists of reproductive gynecology concluded that hysteroscopy is necessary for infertility investigated by Revel and Shushan ${ }^{[22]}$. However, the World Health Organization recommends hysterosalpingography (HSG) for the management of infertile women because HSG provides information on tubal potency or blockage ${ }^{[15,23]}$. World Health Organization recommended hysteroscopy when an intra-uterine abnormality was diagnosed via clinical or complementary examination such as ultrasound and/or HSG or after the failure of in vitro fertilization ${ }^{[24,25]}$. Even so, most of the specialists experience that hysteroscopy is a more accurate tool because of their low false positive and false-negative rates of intrauterine abnormality and as a result, most of the specialist of infertility utilizes hysteroscopy as "first-line routine exam" for infertility patients ${ }^{[26-29]}$. 


\section{CONCLUSIONS}

The study revealed that the hysteroscopy is safe and relatively more accurate in comparison to another procedure to diagnose the patients, who had abnormal uterine bleeding. Therefore, the procedure can be considered as an advantage for women facing infertility problems. The abnormalities and clinical presentations of AUB and other genital tract malignancies have been easily diagnosed by using hysteroscopy as well as it can be operated and treated in the same sitting. The gynecologists prefer hysteroscopy over D\&C USG and/or HSG because these procedures failed to detect cervical or uterine pathologies and cancer as well as the results obtained through this procedure illustrates the high rate of false positive. Therefore, it possibly will lead to the wrong diagnosis and therapeutic decision. Moreover, the outcomes reveled through this procedure are less specific and have had low sensitivity compared to hysteroscopy, therefore fails to identify the lesion.

Our study provided information on the effectiveness and accuracy of hysteroscopy. We concluded that hysteroscopy should be the first and foremost examination to be done for patients experiencing abnormal menstrual and/or abnormal uterine bleeding. As well as it can provide a decisive outline for further improvement in management and follow-up of patient with abnormal uterine bleeding and infertility, thus, benefitting in terms of time loss in reaching to an endpoint for the final accurate diagnosis for the patient. This study is a strong data source that may facilitate innovative ideas among researchers to improve technology.

\section{CONTRIBUTION OF AUTHORS}

Research concept- Dr. Chandravati

Research design- Dr. Malvika Misra

Supervision- Dr. Chandravati

Materials- Dr. Chandravati

Data collection- Dr. Malvika Misra

Data analysis and Interpretation- Dr. Malvika Misra

Literature search- Dr. Malvika Misra

Writing article- Dr. Malvika Misra

Critical review- Dr. Chandravati

Article editing- Dr. Malvika Misra

Final approval- Dr. Chandravati

\section{REFERENCES}

[1] Nicholson WK, Ellison SA, Grason H, Powe NR. Patterns of ambulatory care use for gynecologic conditions: a national study. Am. J. Obstet. Gynecol., 2001; 184: 523-30.

[2] Livingstone M, Fraser IS. Mechanisms of abnormal uterine bleeding. Hum. Reprod. Update, 2002; 8: 6067.

[3] Janet RA, Sharon KH, Robert MW. Abnormal uterine bleeding. Am. Fam. Physician, 2004; 69(8): 1915-26.

[4] Lethaby A, Farquhar C, Sarkis A, Roberts H, Jepson R, et al. Hormone replacement therapy in postmenopausal women: endometrial hyperplasia and irregular bleeding. Cochrane Database Syst. Rev., 2003; 4: CD000402.

[5] ACOG practice bulletin. Clinical management guidelines for obstetrician-gynecologists. Use of botanicals for management of menopausal symptoms. Obstet. Gynecol., 2001; 96(6 suppl): 0111.

[6] Shwayder JM. Pathophysiology of abnormal uterine bleeding. Obstet. Gynecol. Clin. North Am., 2000; 27: 219-34.

[7] Oriel KA, Schrager S. Abnormal uterine bleeding. Am. Fam. Physician, 1999; 60: 1371-80.

[8] Baggish MS. Operative Hysteroscopy. In: Rock JA, Jones HW III, editors. TeLinde's Operative Gynecology $9^{\text {th }}$ ed. Philadelphia: Lippincott Williams \& Wilkins; 2003: 379-411.

[9] Sheth SS, Nerukar NM, Mangeshkar PS. Hysteroscopy in abnormal uterine bleeding. J. Obstet. Gynecol. India, 1990; 40: 451.

[10]Hargreave T, Mellows H. WHO Manual for the Standardized Investigation and Diagnosis of the Infertile Couple, The Press Syndicate of the University of Cambridge, Cambridge, UK, 1993.

[11]Koskas M, Mergui JL, Yazbeck C. Office hysteroscopy for infertility: a series of 557 consecutive cases. Obstet. Gynecol. Int., 2010: 168096.

[12]Price TM, Harris JB. Fulminant hepatic failure due to herpes simplex after hysteroscopy. Obstet. Gynecol., 2001; 98: 954.

[13]Garbin O, Kutnahorsky R, Gollner JL. Vaginoscopic versus conventional approaches to outpatient diagnostic hysteroscopy: a two-centre randomized prospective study. Hum. Reprod., 2006; 21: 2996300. 
[14]Bettocchi S, Ceci O, Di Venere R. Advanced Rowe operative office hysteroscopy without anesthesia: analysis of 501 cases treated with a $5 \mathrm{Fr}$ bipolar electrode. Hum. Reprod., 2002; 17: 2435-38.

[15]Stefanescu A, Marinescu B. Diagnostic hysteroscopyA retrosoective study of 1545 cases. Medica., 2012; 7(4): 309-14.

[16]Kumaresan S, Perumal D. A clinical study of diagnostic hysteroscopy in abnormal uterine bleeding and its histopathological correlation. Int. J. Reprod. Contracept. Obstet. Gynecol., 2018; 7: 396400.

[17]De Sa Rosa e de Silva AC, Rosa e Silva JC, Candido dos Reis FJ. Routine office hysteroscopy in the investigation of infertile couples before assisted reproduction. J. Reprod. Med., 2005; 50(7): 501-06.

[18]Krampl E, Bourne T, Hurlen-Solbakken $H$, Istre $O$. Transvaginal ultrasonography, sonohysterography and operative hysteroscopy for the evaluation of abnormal uterine bleeding. Acta. Obstet. Gynecol. Scand., 2001; 80: 616-22.

[19]Panda A, Parulekar SV, Gupta A. Diagnostic hysteroscopy in abnormal uterine bleeding and its histopathological correlation. J. Obstet. Gynecol. India, 1999; 175: 74-76.

[20]Gianninoto A, Morana C, Campione C. Diagnostic hysteroscopy in abnormal uterine bleeding. Five years experience. Minerva. Ginecol., 2003; 55: 5761.

[21]VanTrotsenburg $M$, Wieser $F$, Naegle F. Diagnostic hysteroscopy for the investigation of abnormal uterine bleeding in premenopausal patients. Contrib. Gynecol. Obstet., 2000; 20: 21-26.
[22]Revel A, Shushan A. Investigation of infertile couple/Hysteroscopy with Endometrial biopsy is the goal standard investigation for AUB. Human Reprod. Hum. Reprod., 2002; 17(8): 1947-49.

[23]Oriel KA, Schrager S. Abnormal uterine bleeding. Am. Fam. Physician, 1999; 60(5): 1371-80.

[24]Golan A, Eilat E, Ron-El R. Hysteroscopy is superior to hysterosalpingography in infertility investigation. Acta. Obstet. Gynecol. Scand., 1996; 75: 654-56. doi: 10.3109/00016349609054692.

[25]Wang CW, Lee CL, Lay YM. Comparison of hysterosalpingography and hysteroscopy in female infertility. J. Am. Assoc. Gynecol. Laparosc., 1996; 3:581-84.

[26]Prevedourakis C, Loutradis D, Kalianidis C, et al. Hysterosalpingogra phy and hysteroscopy in female infertility. Hum. Reprod., 1994; 9: 2353-55. doi: 10.1093/oxfordjournals. humrep.a138451.

[27]Goldstein SR, Zeltser I, Horan CK, Snyder JR, Schwartz LB.Ultrasonography-based triage for perimenopausal patients with abnormal uterine bleeding. Am. J. Obstet. Gynecol., 1997; 177: 102-08.

[28]Dijkhuizen FP, Mol BW, Brolmann HA, Heintz AP. The accuracy of endometrial sampling in the diagnosis of patients with endometrial carcinoma and hyperplasia: a meta-analysis. Cancer, 2000; 8: 176572. doi: 10.1002/1097-0142(20001015)89:8<1765::Al D-CNCR17>3.0.CO;2-F.

[29]Rosenthal AN, Panoskaltsis T, Smith T, Soutter WP. The frequency of significant pathology in women attending a general gynaecological service for postcoital bleeding. BJOG, 2001; 108: 103-06. 